\title{
Toughening of carbon fibre reinforced polymer composites with rubber nanoparticles for advanced industrial applications
}

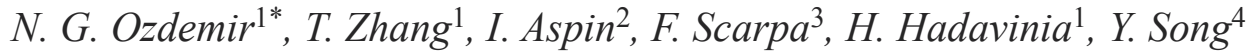 \\ ${ }^{1}$ Kingston University London, SW15 3DW, United Kingdom \\ ${ }^{2}$ Cytec Industrial Materials, DE75 7SP, United Kingdom \\ ${ }^{3}$ ACCIS, University of Bristol, BS8 1TR, United Kingdom \\ ${ }^{4}$ School of Energy Science and Engineering, University of Energy School and Technology of China, 611731 Chengdu, \\ China
}

\begin{abstract}
This study investigates the effects of nano carboxylic acrylonitrile butadiene rubber (CNBR-NP) and nano acrylonitrile butadiene rubber (NBR-NP) on the interlaminar shear strength and fracture toughness of carbon fibre reinforced polymer composites (CFRP) with dicyandiamide-cured epoxy matrix. The results show that nano-size dispersion of rubber significantly improved the Mode I delamination fracture toughness $\left(G_{\mathrm{IC}}\right)$ of the CFRP by $250 \%$ and its Mode II delamination fracture toughness $\left(G_{\mathrm{IIC}}\right)$ by $80 \%$ with the addition of $20 \mathrm{phr}$ of CNBR-NP. For the NBR-NP system, the $G_{\mathrm{IC}}$ and $G_{\text {IIC }}$ delamination fracture toughness of the CFRP were increased by 200 and $80 \%$ respectively with the addition of $20 \mathrm{phr}$ (parts per hundred rubber) of nano rubber to the matrix. Scanning electron microscopy (SEM) images of the fracture surface revealed that the toughening was mainly achieved by debonding of the nano rubber, crack path deflection and fibre bridging.
\end{abstract}

Keywords: polymer composites, processing technologies, nanomaterials, mechanical properties, nanocomposites

\section{Introduction}

Carbon fibre reinforced polymer composites (CFRP) are widely used in advanced engineering technologies. Epoxy resins are employed as their matrix material, possessing outstanding mechanical performance and good processability. However, epoxy resins are relatively brittle which causes a major problem for the engineering performance of the final structure. To overcome this weakness, scientists have been toughening the formulations with nano and micron-scale particles in the last three decades.

Several research teams have explored the modification of the properties of epoxy resins by introducing various toughening agents such as reactive liquid rubber [1], thermoplastics [2, 3], micron scale rubber particles, nano rubber particles $[4,8]$, and nanoscale fillers $[5,6]$. One of the main objectives behind the modification of the epoxy is to improve the fracture toughness of the resin without sacrificing intrinsic properties like the glass transition temperature $\left(T_{\mathrm{g}}\right)$ and its elastic modulus. A significant increase in the fracture toughness of advanced composite laminates can constitute a potential route towards designing composites with an extended lifetime and durability.

Recent studies have demonstrated the benefits of using nanoparticles to improve the mechanical prop-

\footnotetext{
${ }^{*}$ Corresponding author, e-mail: gulsine@yahoo.com

(C) BME-PT
} 
erties of epoxy resins. Tang et al. [7] reported a 52\% increase in the $K_{\mathrm{IC}}$ of epoxy resin with $0.2 \mathrm{wt} \%$ highly dispersed thermally reduced graphene sheets addition. Qi et al. [8] observed an improvement of the Izod impact strength of epoxy by $80 \%$ when dispersing $12 \mathrm{phr}$ of nano acrylonitrile butadiene rubber. Phong et al. [9] observed a 70\% increase in the mode I interlaminar fracture toughness of CFRP using epoxy matrix modified with $35 \mathrm{~nm}$ core-shell nano rubber at crack initiation. Fan et al. [10] evaluated the mechanical properties of nano rubber toughened epoxy resin and observed an improvement of $96 \%$ in Izod impact strength adding $12 \mathrm{phr}$ of nano carboxylic nitrile butadiene rubber. Tripathi and Srivastava [11] improved the Izod impact strength and toughness of epoxy by 1.5 times with a $20 \mathrm{wt} \%$ dispersion of carboxyl terminated butadiene acrylonitrile copolymer (CTBN), however with a resulting slight decrease of the system $T_{\mathrm{g}}$. In a recent review paper by Tang et al. [12], the highest improvements in the fracture toughness of FRP was achieved in hybrid composites, where the tougheners are silica particles and CTBN rubber. Hsieh et al. [13] demonstrated that it is possible to improve the interlaminar fracture toughness of CFRP by a factor of 2 with $10 \mathrm{wt} \%$ of silica and $9 \mathrm{wt} \%$ of CTBN addition to the epoxy matrix. In many of these studies, the drawbacks such as the high cost of the nanoparticles, the complicated processing methods and the inevitable decay in the $T_{\mathrm{g}}$ of the system restricted the large-scale production of these nano composites.

In our previous work, the effect of acrylonitrilebased nanorubbers on the cure kinetics, physical properties and the processing of epoxy resin were studied. We have showed that the acrylonitrile based nanorubber materials do not increase the viscosity of the specific epoxy resin beyond its processing limits; neither do they affect the $T_{\mathrm{g}}$ of the system [14]. Hence, previous work deals with the properties of the nanorubber-toughened matrix resin only, and the current work represents a continuation, studying the mechanical properties of the CFRP composites with the nanorubber toughened epoxy resin matrices. In a recent work we have also shown that nanorubber toughening of the resin can improve the damping capacity of the matrix, leading to an enhanced fatigue life [15].

In general, a significant improvement in the fracture toughness of the composites with the addition of nanorubber to their matrices is usually accompanied by a modification of the glass transition temperature $\left(T_{\mathrm{g}}\right)$ [16]. The work proposed in this paper is novel because it presents for the first time - to the best of the Authors' knowledge - a class of composites for which none of the intrinsic properties are deteriorated by the dispersion of nanorubber into their matrices [14]. The composites we present in this work feature a significant improvement in the delamination fracture toughness without any noticeable change in the $T_{\mathrm{g}}$.

NBR-NP and CNBR-NP, both of which impart excellent compatibility with epoxy resins, are dispersed within dicyandiamide-cured epoxy matrices. To the best of the Authors' knowledge, due to the challenges in nano rubber dispersion within epoxy matrices and the complex structure and cross-linking mechanism of the dicyandiamide (DICY) curing agent, no previous study was reported on the toughening of dicyandiamide-cured epoxy matrix with acrylonitrile-based nano rubber materials. This forms the primary motivation of the current work.

A significant amount of work is available in the literature on the effect of the addition of nano rubber on the mechanical properties of epoxy resin systems [17-19]. However, there is a noticeable lack of work on the mechanical properties of CFRPs with nano rubber-toughened epoxy as matrix, mainly because of the viscosity build-up of the resin upon addition of nano rubber, which makes the penetration of the nano-modified resin through the fibres difficult. In this paper, we describe the analysis on CFRP produced by the hand lay-up technique. The hand lay-up process is not affected by viscosity changes, and - moreover - the relatively high viscosity of nano-modified matrices prevent resin leakage at high processing pressures, resulting therefore in improved interfacial properties.

Epoxy matrices were toughened with nano rubber by using a laboratory-scale triple mill. Narrow particle size and even distribution were maintained in the blends by this technique, resulting in a toughened epoxy network with enhanced mechanical properties.

We report novel CFRP composites with acrylonitrile based nano rubber-modified resin matrices with significantly improved fracture toughness and the ductility. The manufacturing methods used to produce the matrices and the composites could be potentially applied to scale-up processes in industry. 
2. Materials and composites manufacturing Liquid DGEBA (diglycidyl ether of Bisphenol A) (Araldite LY1556) with epoxide equivalent weight of 188 was supplied by Huntsman, UK. Dicyandiamide (DICY, Dyhard D50EP) was employed as the curing agent and a difunctional urone (Dyhard UR500) was used as the accelerator, both from AlzChem, UK. Nano carboxylic acrylonitrile butadiene rubber (CNBR-NP) Narpow VP-501 (single particle size distribution $50-100 \mathrm{~nm}$, acrylonitrile content, $26 \mathrm{wt} \%$ ), and nano acrylonitrile butadiene rubber (NBR-NP) Narpow VP-401 (single particle size distribution 100-150 nm, acrylonitrile content, $26 \mathrm{wt} \%$ ) were received in powder form from SINOPEC, Beijing Research Institute of Chemical Industry (BRICI), China. For the details on the chemical reactions occurring between the components of the DGEBA resin, the DICY hardener and the difunctional urone accelerator the reader is referred to $[20,21]$.

Fumed silica (FS) received from Aerosil, UK $\left(D_{50}=\right.$ $1 \mu \mathrm{m}$ ) was adopted in some of the formulations to modify the rheological behaviour and help the CFRP laminates production. 199 GSM and $2 \times 2$ Twill carbon plies from Sigmatex (UK) Ltd. (Torayca T300) were employed to produce the CFRP panels. The matrix formulations used in this research work are given in Table 1.

The nano rubber was dispersed in the DGEBA matrix and the blend was speed-mixed at $3500 \mathrm{rpm}$ for 1 minute. The blend was triple milled for six times at room temperature $\left(R T=23^{\circ} \mathrm{C}\right)$. After mixing, it was then magnetically stirred at a speed of $320 \mathrm{rpm}$ and degassed at $70^{\circ} \mathrm{C}$ inside a glass flask for 16 hours under vacuum. The curing agent and the accelerator were added and the final mixture was speed-mixed at $2100 \mathrm{rpm}$ for 6 minutes. Further details on the manufacturing techniques adopted can be found in [14].

A hand lay-up technique was used to produce the CFRP laminates. Bidirectional dry carbon plies with the nano rubber-toughened matrix were vacuum bagged and cured in an autoclave under a pressure of $6 \mathrm{~atm}$. Twelve and eight layers of carbon plies were used to fabricate samples for double cantilever beam tests and interlaminar shear strength (ILSS) tests, respectively. The composite panels were heated to $120^{\circ} \mathrm{C}$ at a heating rate of $0.5^{\circ} \mathrm{C} / \mathrm{min}$ and held for 1 hour at this temperature before cooling down to $R T$ at the same rate, in an autoclave. The processing techniques are given in Figure 1.

The volume fraction of the carbon fibres in the composites was estimated with the Equation (1):

$V_{\mathrm{f}}[\%]=\frac{100 W_{\mathrm{FAW}} N_{\mathrm{p}}}{B \rho_{\mathrm{F}}}$

where $W_{\text {FAW }}$ is the fibre areal weight, $N_{\mathrm{p}}$ is the number of plies, $B$ is the thickness of the composites and $\rho_{\mathrm{F}}$ is the density of the carbon fibre. The value of $W_{\text {FAW }}$ is quoted from the manufacturer's datasheet of the carbon fabrics, $\left(199 \mathrm{~g} / \mathrm{m}^{2}\right)$. The density of the carbon fibre is $1.76 \mathrm{~g} / \mathrm{cm}^{3}$. The carbon fibre volume fraction of the composites was $52 \pm 1 \%$.

\section{Experimental work}

\subsection{Short beam shear (SBS) test}

Specimens with dimensions $20 \times 6.35 \times 3.2 \mathrm{~mm}$ were cut from the CFRP panels using a water jet. The SBS tests were conducted complying with ASTM D2344 at a crosshead speed of $1.3 \mathrm{~mm} / \mathrm{min}$ using Zwick Z250 universal testing machine at $R T\left(23^{\circ} \mathrm{C}\right)$. Test samples were placed on two roller supports that allow lateral motion and loaded at mid-span. The span length $(S)$ to specimen thickness $(t)$ ratio was 5 . The beam was loaded until failure and the failure load was used to calculate the apparent interlaminar shear strength (APS) of the composites. The maximum load was interpreted as the initial maximum attained on load vs. crosshead displacement graphs. The $A P S$ was calculated by Equation (2):

$A P S=\frac{0.75 P_{\max }}{w t}$

where $P_{\max }$ represents the maximum load, $w$ the width of the specimen and $t$ the thickness of the specimen. Five samples were tested for each composition.

Table 1. Formulations used within experimental work, in phr (parts per hundred of DGEBA)

\begin{tabular}{|l|c|c|c|c|c|c|}
\hline \multicolumn{1}{|c|}{ CODE } & DGEBA & DICY & Diurone & NBR-NP & CNBR-NP & Fumed Silica \\
\hline R & 100 & 14 & 6 & - & - & - \\
\hline R/ X FS & 100 & 14 & 6 & - & - & $X$ \\
\hline X CNBR-NP/ R & 100 & 14 & 6 & - & $X$ & - \\
\hline X NBR-NP/R & 100 & 14 & 6 & $X$ & - & - \\
\hline
\end{tabular}



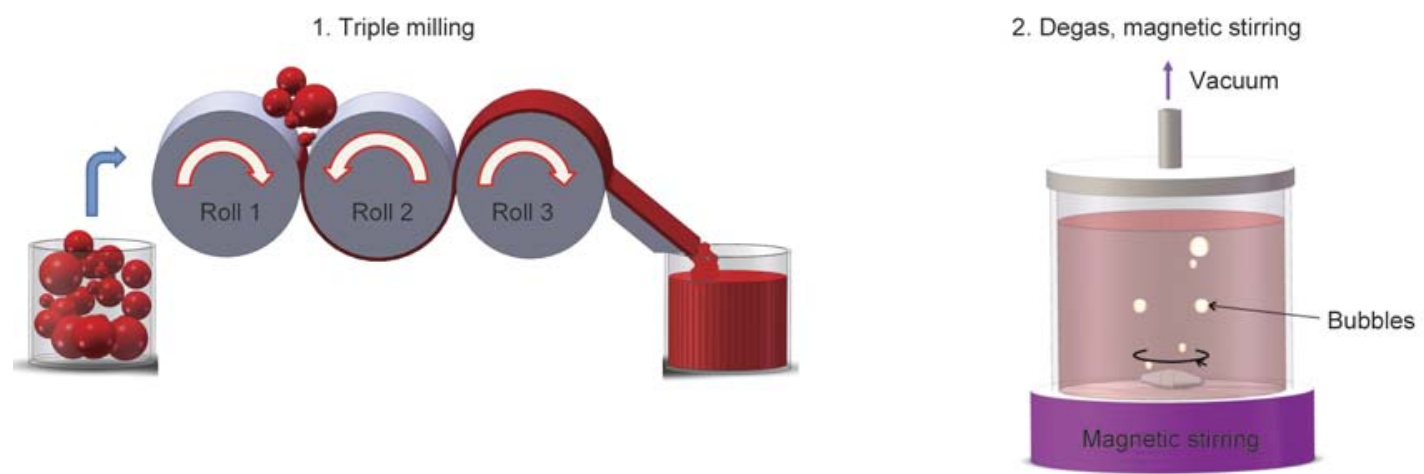

3. Speed mixing
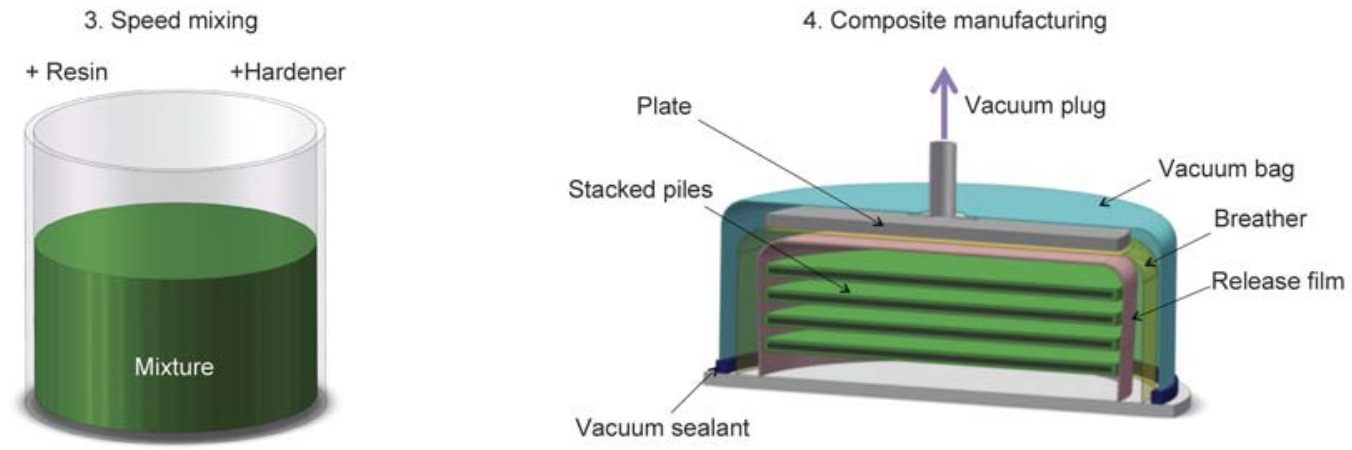

Figure 1. Manufacturing techniques used in this study

\subsection{Mode I delamination fracture toughness using DCB specimen}

The effect of nano rubber toughening on Mode I delamination toughness $G_{1 \mathrm{C}}$, was studied using a double cantilever beam (DCB) test on CFRP samples following the EN6033 standard by using a Zwick Z250 machine at a crosshead speed of $10 \mathrm{~mm} / \mathrm{min}$. The samples were loaded perpendicular to the delamination surfaces.

A piece of release film (PTFE film) was placed at the midplane of the stacked plies during the hand lay-up process to create a $30 \mathrm{~mm}$ long pre-crack. Five DCB specimens with dimensions of $250 \times 25 \times 3 \mathrm{~mm}$ were tested from each formulation. Screw able grips were clamped onto the two faces of the specimen end having the pre-crack. The specimens' edges were coated with white paint and marked for a clear reading of the crack length. The pre-cracked sample was loaded continuously by peel-forces until a total propagated crack length of approximately $100 \mathrm{~mm}$ was achieved. The interlaminar fracture toughness energy was calculated from the propagated crack length and the applied energy determined from the load-cross head displacement diagram. Five samples were tested for each composition.

The interlaminar fracture toughness is calculated from the Equation (3):

$$
G_{\text {IC }}=\frac{A}{a w} \cdot 10^{6}
$$

where $G_{\mathrm{IC}}$ is the fracture toughness, in $\left[\mathrm{J} / \mathrm{m}^{2}\right], A$ is the required energy to achieve the total propagated crack length, in Joules (integration of the area under the load vs. crosshead displacement diagram), $a$ is the crack length, in [mm] (final crack length minus initial crack length), $w$ is the width of the specimen, [mm].

Scanning electron microscopy (SEM) at secondary electron mode was used to verify the distribution of the nano rubber within the resin matrix and the toughening mechanisms. For this, fracture surfaces of the CFRP laminates were examined. The samples were vacuum coated with gold using a sputter coater. Images were taken using an accelerating voltage of $20-25 \mathrm{keV}$ with a magnification between 90 to 2000 times.

\subsection{Mode II interlaminar fracture toughness (end notched flexure test)}

Five specimens for each composite configuration were tested following the EN6034 standard with Zwick Z50 machine at a crosshead speed of $1 \mathrm{~mm} / \mathrm{min}$. The samples were positioned on a threepoint bend fixture with a total span of $100 \mathrm{~mm}$; with an initial crack length of $34-35 \mathrm{~mm}$. 
The load and crosshead movement were continuously recorded and the crack length was recorded using a digital video camera. The sample was unloaded when the maximum load is reached. The mode II fracture toughness, $G_{\text {IIC, }}$ was calculated using the maximum load sustained by the sample.

The $G_{\text {IIC }}$ value was calculated $[22,23]$ as given by Equation (4):

$G_{\mathrm{IIC}}=\frac{9000 P a^{2} \delta}{2 w\left(\frac{1}{4} L^{3}+3 a^{3}\right)}$

where $G_{\text {IIC }}$ is the Mode II fracture toughness energy in $\left[\mathrm{J} / \mathrm{m}^{2}\right], P$ is the load $[\mathrm{N}], \delta$ is the crosshead displacement at the crack growth onset [mm], $w$ the specimen width $[\mathrm{mm}], a$ the initial crack length $[\mathrm{mm}]$ and $L$ the span length [mm]. Five samples were tested for each composition.

\section{Results and discussion}

\subsection{Morphology}

Figure 2 shows fracture surfaces of the CFRP samples. The nano rubber appears to have bonded to the surface of the carbon fibre and debonded from the matrix. In this figure, both CNBR-NP and NBR-NP provide an even dispersion within the composites.

In the NBR-NP modified resins, an interphase formed between the carbon fibre and the matrix that is an indication of a strong fibre-matrix interfacial adhesion (Figure 2b). This suggests that the NBR-NP developed a resistance to fibre-matrix failure. It is possible that the NBR-NP particles act like a sizing agent for the carbon fibres, therefore enhancing the fibre-matrix interfacial strength. It is clear from the
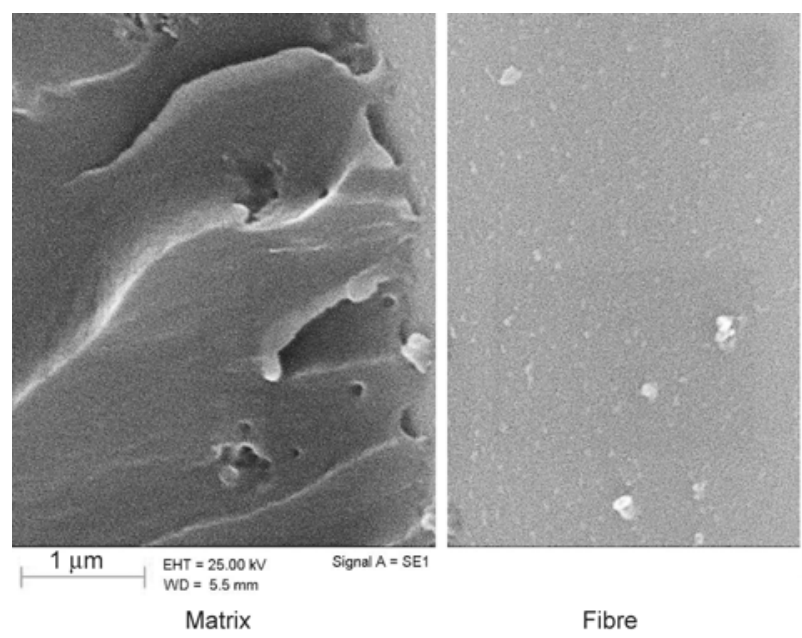

a) inspection of Figure $2 b$ that the NBR-NP particles are attached to the fibre surface, creating a higher contact area between the latter and forming mechanical interlocking sites [24].

In CFRP composites, the difference between the elastic moduli of the carbon fibre and the resin matrix is quite significant and the stress transfer between the two phases is weak, creating residual stresses at the interface. However, the relatively compliant nanorubber toughened matrix can deform plastically, therefore relaxing the stress concentrations [15]. Plastic deformation at the fibre-matrix interface may act as an energy dissipation mechanism that provides an improved interfacial strength. The soft particles resist to fibre-matrix failure due to the creation of an interphase, as shown in Figure 2b.

Interestingly, this kind of interphase was not observed in the laminates with the unmodified matrix and the CNBR-NP modified matrices.

Figure 3 shows the SEM images of the matrix fracture surface in between the carbon fibres. It can be seen that the dispersion of CNBR-NP in epoxy resin is better when compared to that of NBR-NP. This is due to the carboxyl group of CNBR-NP, helping with better dispersion in the matrix [25]. Further details on the morphology of these blends can be found in [14]. The toughening mechanisms of both systems were identified as crack front pinning, crack path deflection, crack bridging and nano rubber debonding, the latter followed by plastic void growth of the epoxy (Figure 3). In crack front pinning mechanism, crack growth is prevented by the rigid particles and hence, extra energy is required for crack propagation [26]. In crack path deflection mechanism, nanoparticles
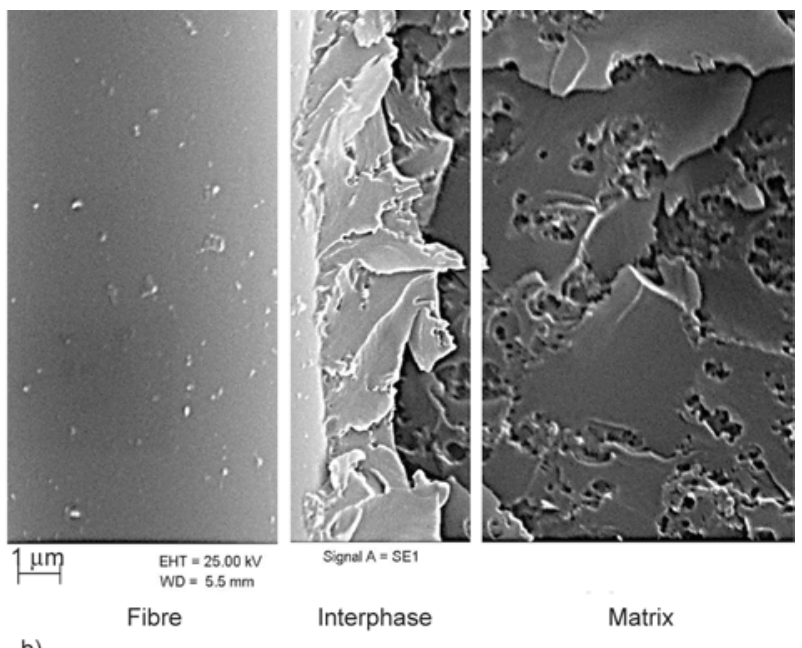

b)

Figure 2. SEM image of the fracture surface of (a) CFRP with 20CNBR-NP/ R matrix, (b) CFRP with 10NBR-NP/ R matrix 
deviate the crack from its main plane resulting in an increase in the surface area of the crack and the energy to propagate such a crack. In crack bridging mechanism, the particles link separate crack surfaces to each other and reduce the stress concentration at the crack tips. Presence of holes with larger diameters than the particles within the structures shows that plastic void growth of the epoxy matrix, initiated by debonding of the particles has occurred [27-29]. Matrix-particle debonding is essential in the plastic void growth mechanism, which is a sig- nificant part of the plastic deformation in nano rubber modified epoxy samples that reduces the stress at the crack tip [30,31]. From the observation of the micrographs in Figure 3 it is possible to note the presence of a non-homogeneous void size distribution, with some of the voids larger than the nanorubber diameter (CNBR-NP, $50-100 \mathrm{~nm}$ or NBRNP, $100-150 \mathrm{~nm}$ ). This fact proves that the debonding mechanism follows a plastic void growth, which is major energy dissipation and hence a toughening micro mechanism [32]. Rubber nano particle debond-

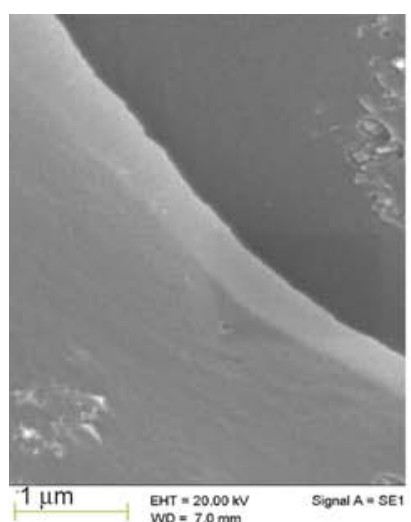

a) R 6 1FS

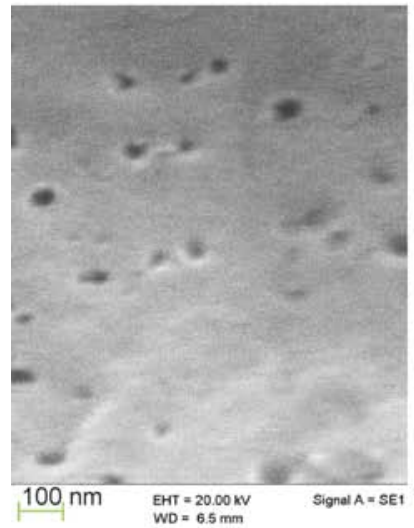

b) 5 CNBR-NP/R

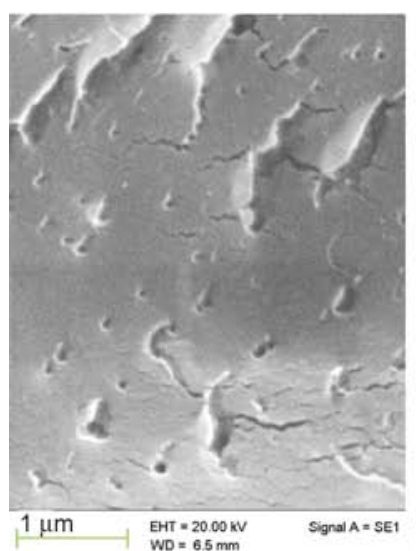

f) 5 NBR-NP/R

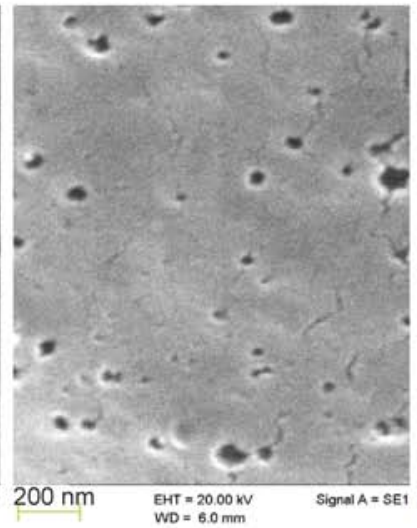

c) $10 \mathrm{CNBR}-\mathrm{NP} / \mathrm{R}$

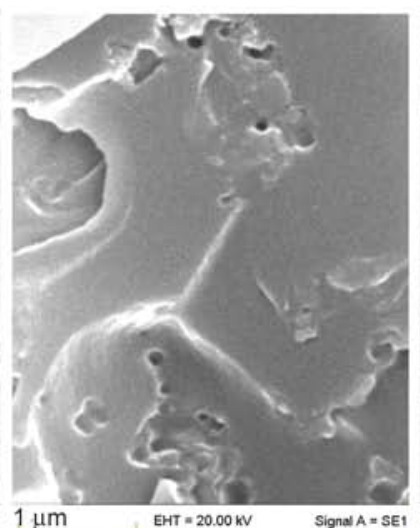

g) 10NBR-NP/ R

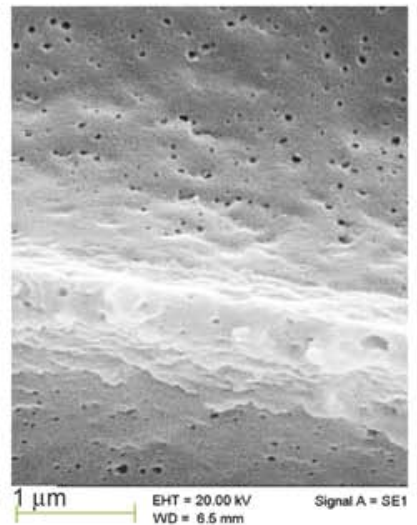

d) 15 CNBR-NP/R

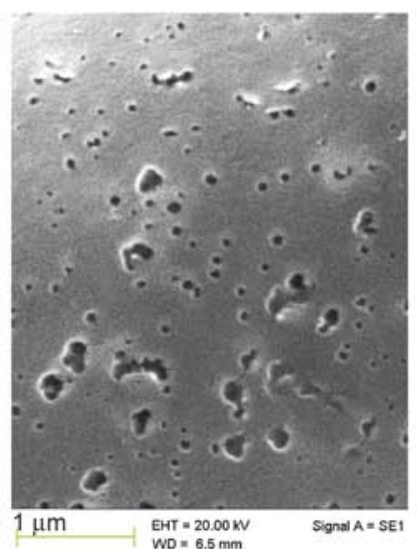

h) $15 N B R-N P / R$

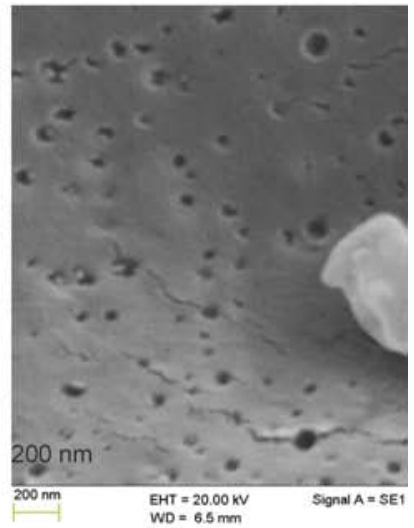

e) 20CNBR-NP/R

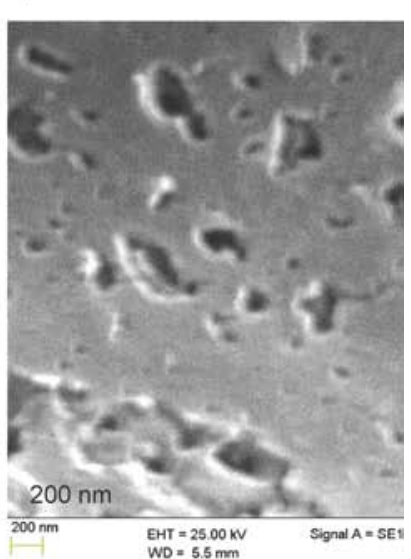

i) 20 NBR-NP/R

Figure 3. SEM images of the matrices on the DCB fracture surface of R 6 1FS (a), CNBR-NP/ R (b-e), NBR-NP/ R (f-i) 
ing from the resin matrix occurs at the particle-matrix interface, therefore reducing the degree of stresses acting in the matrix adjacent to the particles.

\subsection{Interlaminar shear behaviour}

The apparent interlaminar shear strength and the failure stresses and corresponding strains are given in Table 2. For each laminate tested, a load-displacement curve that represents the average of the five samples is shown Figures $4 a$ and $4 b$. Figure $4 c$ shows the behaviour of the apparent interlaminar shear strength $[\mathrm{MPa}]$ vs. the nanorubber loading $[\mathrm{phr}]$ for the CFRP samples.

The response of each laminate shows a nearly linear elastic behaviour at the early stages of loading. This continues until an apparent elastic limit is reached. After this point, each laminate shows a decrease in load. This decrease in load is sudden in brittle composites, like CFRP with a neat resin matrix. However, with an increase in the nano rubber concentra-

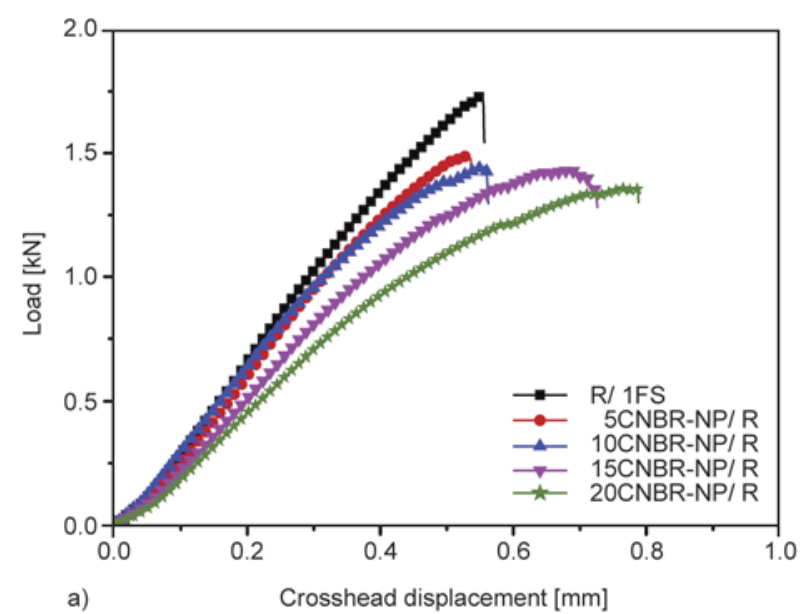

Table 2. Apparent interlaminar shear strength of the CFRP samples, $\sigma-$ standard deviation, $s-$ displacement at fracture

\begin{tabular}{|c|c|c|c|c|c|c|}
\hline \multirow{2}{*}{ X (NP phr) } & \multicolumn{2}{|c|}{ X CNBR-NP/ R } & \multicolumn{3}{c|}{ X NBR-NP/ R } \\
\cline { 2 - 7 } & $\begin{array}{c}\boldsymbol{A P S} \\
{[\mathbf{M P a}]}\end{array}$ & $\begin{array}{c}\boldsymbol{\sigma} \\
{[\mathbf{M P a}]}\end{array}$ & $\begin{array}{c}\boldsymbol{s} \\
{[\mathbf{m m}]}\end{array}$ & $\begin{array}{c}\boldsymbol{A P S} \\
{[\mathbf{M P a}]}\end{array}$ & $\begin{array}{c}\boldsymbol{\sigma} \\
{[\mathbf{M P a}]}\end{array}$ & $\begin{array}{c}\boldsymbol{s} \\
{[\mathbf{m m}]}\end{array}$ \\
\hline $0(0.26 \mathrm{FS})$ & 71.5 & 1.7 & 0.6 & 71.5 & 1.7 & 0.6 \\
\hline $0(1 \mathrm{FS})$ & 70.1 & 1.1 & 0.6 & 70.1 & 1.1 & 0.6 \\
\hline 5 & 67.8 & 0.6 & 0.5 & 68.8 & 0.7 & 0.7 \\
\hline 10 & 62.6 & 1.2 & 0.6 & 62.0 & 0.6 & 0.8 \\
\hline 15 & 61.0 & 0.4 & 0.7 & 56.6 & 0.1 & 0.7 \\
\hline 20 & 55.6 & 0.8 & 0.8 & 54.0 & 1.5 & 0.9 \\
\hline
\end{tabular}

tion, the decrease in load is ductile and apparently the crosshead displacement till fracture is larger and increases continuously with the rubber content in the samples. This increase in crosshead displacement is due to a decrease in the composite stiffness with rubber concentration, which results in higher deflections at the same load levels. Bai et al. [33] previously reported that in the linear part of the loaddisplacement curve fibre fragmentation was observed

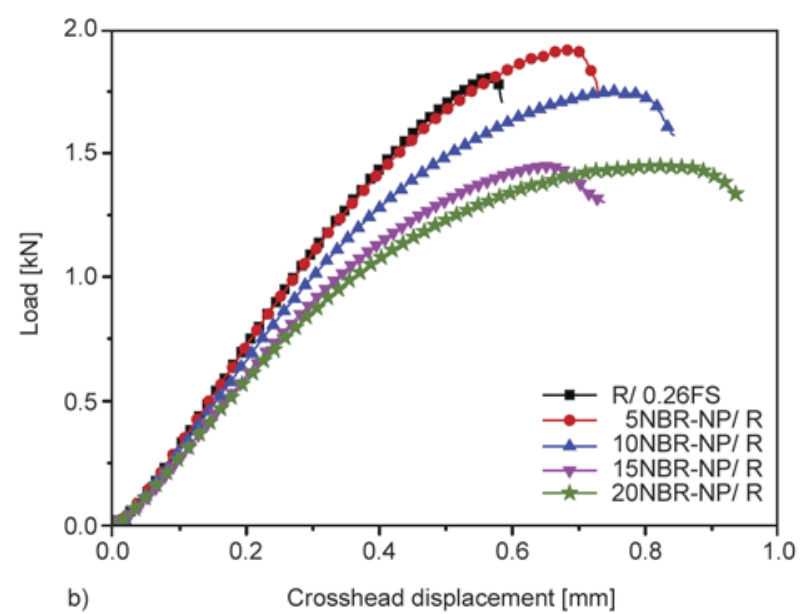

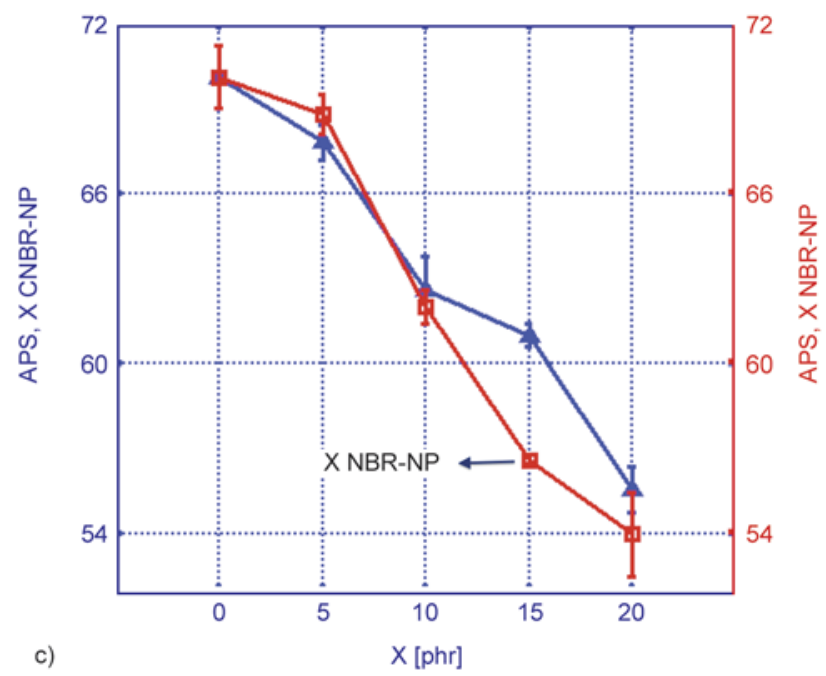

Figure 4. Load vs. crosshead $(\mathrm{CH})$ displacement graph of CFRP in ILSS specimens with (a) X CNBR-NP/ R matrix, (b) X NBR-NP/ R matrix, (c) apparent interlaminar shear strength [MPa] vs. X [phr] of the CFRP samples 
in the central part of the beam, and matrix damage was noticed on the shearing section resulting in the non-linearity of load vs. displacement curve. Figure 4 shows that with an increase in nano rubber concentration, the linearity of the curve until failure decreases, indicating higher matrix damage.

The results show that CFRP with neat R/ 1FS matrix reached the highest peak load, and the apparent interlaminar shear strength (APS) decreased continuously with an increase in the rubber loading. Fumed silica did not show a noticeable effect on the results. The decrease in the APS values is attributed to the low strength and stiffness of the nano rubber particles decreasing the final strength and stiffness of the laminates, which is an expected phenomenon in nano rubber modified CFRPs.

\section{Failure modes of the short beam shear specimens}

The failed short beam specimens were examined with SEM at secondary electron mode to assess the damage in the laminates. In Figures $5 \mathrm{a}$ and $5 \mathrm{~b}$ delamination and fibre buckling is observed in the CFRPs with the neat R/ $1 F S$ matrix. In Figures $5 \mathrm{c}$ and $5 \mathrm{~d}$ it is possible to observe that the tensile stress generated at the bottom of the specimen has caused transverse tensile cracks. Delamination is also observed between the carbon ply and the matrix in Figures $5 \mathrm{c}-$ $5 \mathrm{f}$, and fibre pull-out due to delamination is present in Figures $5 \mathrm{~d}$ and $5 \mathrm{f}$. In Figures $5 \mathrm{e}$ and $5 \mathrm{~h}$ cracks at $45^{\circ}$ are observed due to the maximum shear stress occurring in $\pm 45^{\circ}$ directions under uniaxial loading. Failure did not occur at the mid-plane in any of the specimens. Instead, interfacial shear failure occurred above and below the mid-plane.

From the analysis of the SEM images (Figure 3) it is clear that the level of porosity in the structure increases with the nanorubber loading. Voids cause a reduction in the apparent shear strength by decreasing the net cross sectional area and by creating stress concentrations [34]. Another factor affecting the APS value is the thickness of the interlaminar layers. Previous studies have shown that an increase of the interply resin thickness enhances the interlaminar mechanical properties [35]. Small thickness variations arising from differences in resin content of the composites may result in different interlaminar properties. A most important factor is also the degree of crosslinking [36]. The morphology and the change in stoichiometry of the matrix with the nanorubber dispersion can affect the interlaminar shear stiffness and strength properties. However, we have proved with dynamic mechanical analysis that the change in the degree of crosslinking with the nanorubber modification is insignificant [14].

To summarise, the consistent decrease of the APS value with the nanorubber concentration may be explained by the lower quality of the laminates with high void content, and by the low stiffness of the nanorubber particles that cause a reduction in the stiffness of the resin.

\subsection{Mode I fracture toughness using double cantilever beam (DCB)}

The Mode I fracture toughness of the CFRP laminates based on an average of 5 samples are summarised in Table 3. One can observe a 250 and 200\% increase in $G_{\text {IC }}$ with $20 \mathrm{phr}$ CNBR-NP and NBR$\mathrm{NP}$ addition to the matrix, respectively.

Figures 6 shows the load vs. displacement curves of the CFRP samples with the CNBR-NP and NBRNP modified matrices respectively. This figure shows that the maximum load and crosshead displacement attained before fracture increases consistently with increasing the nano rubber concentration. Figure 6 also indicates that the force linearly increases until it reaches the maximum force value, and then gradually decreases with zigzag shape in the propagation stages. This could be due to the variations of resin-rich regions or fibre-rich regions along the longitudinal directions $[37,38]$.

The fracture process was recorded by a video camera to analyse the crack initiation and propagation. In Figure 7a, the crack propagation is rather brittle and no microcrack formation is observed in the CFRP panel with R/ 1FS matrix. However, in the laminate with 20CNBR-NP/ R matrix, high amount of microcrack formation was observed and the crack often deviated from its path (Figure 7b). Such crack propagation in zig-zag manners showing meandering paths required a higher driving force and created a larger fracture area, resulting in higher frac-

Table 3. $G_{\mathrm{IC}}$ test data, $\sigma-$ standard deviation

\begin{tabular}{|c|c|c|c|c|c|c|}
\hline \multirow{2}{*}{$\begin{array}{c}\mathbf{X} \\
{[\mathbf{p h r}]}\end{array}$} & \multicolumn{2}{|c|}{$\mathbf{X} \mathbf{C N B R}-\mathbf{N P} / \mathbf{R}$} & \multicolumn{3}{|c|}{$\mathbf{X}$ NBR-NP/ R } \\
\cline { 2 - 7 } & $\begin{array}{c}\boldsymbol{G}_{\mathbf{I C}} \\
{\left[\mathbf{J} / \mathbf{m}^{\mathbf{2}}\right]}\end{array}$ & $\begin{array}{c}\boldsymbol{\sigma} \\
{\left[\mathbf{J} / \mathbf{m}^{\mathbf{2}}\right]}\end{array}$ & $\begin{array}{c}\mathbf{I n c r e a s e} \\
{[\%]}\end{array}$ & $\begin{array}{c}\boldsymbol{G}_{\mathbf{I C}} \\
{\left[\mathbf{J} / \mathbf{m}^{\mathbf{2}}\right]}\end{array}$ & $\begin{array}{c}\boldsymbol{\sigma} \\
{\left[\mathbf{J} / \mathbf{m}^{\mathbf{2}}\right]}\end{array}$ & $\begin{array}{c}\text { Increase } \\
{[\%]}\end{array}$ \\
\hline $0(1 \mathrm{FS})$ & 372 & 32 & - & - & - & - \\
\hline 5 & 517 & 24 & 39 & 510 & 20 & 37 \\
\hline 10 & 840 & 15 & 126 & 803 & 29 & 116 \\
\hline 15 & 950 & 102 & 155 & 926 & 56 & 149 \\
\hline 20 & 1305 & 105 & 251 & 1127 & 89 & 203 \\
\hline
\end{tabular}




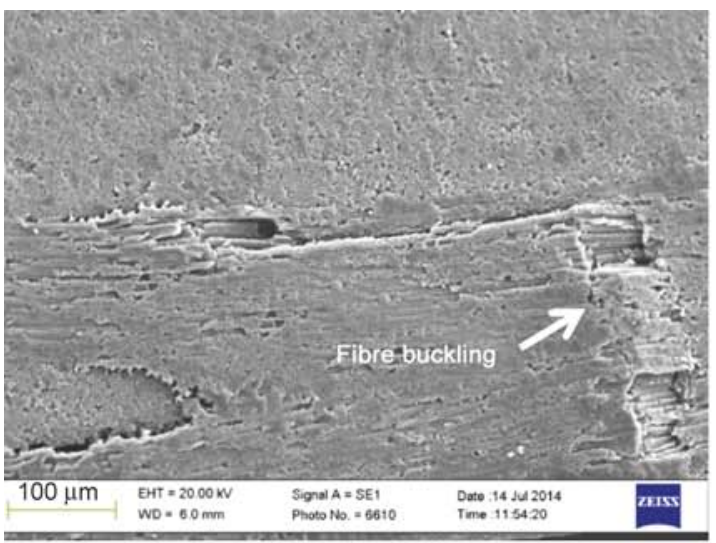

a)

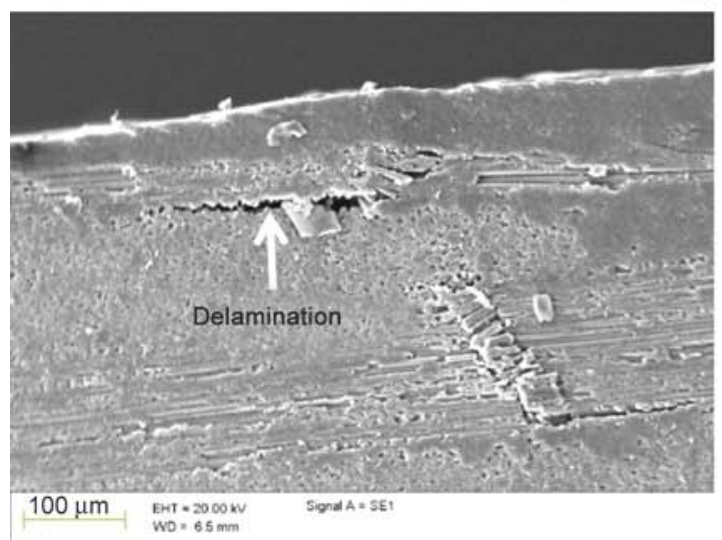

c)

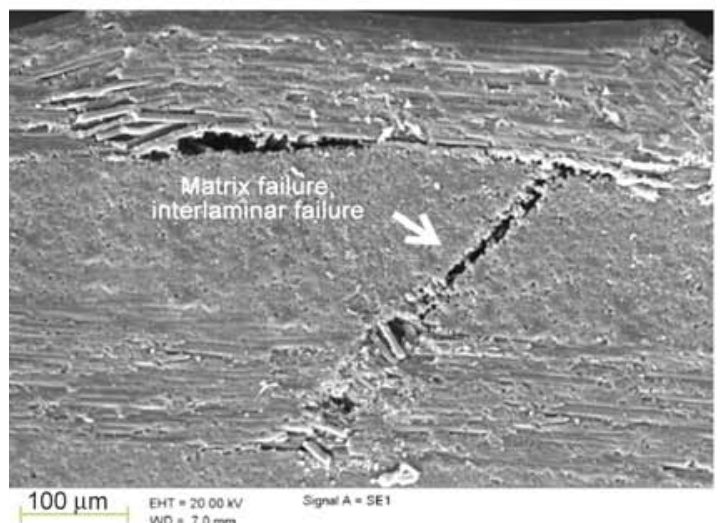

e)

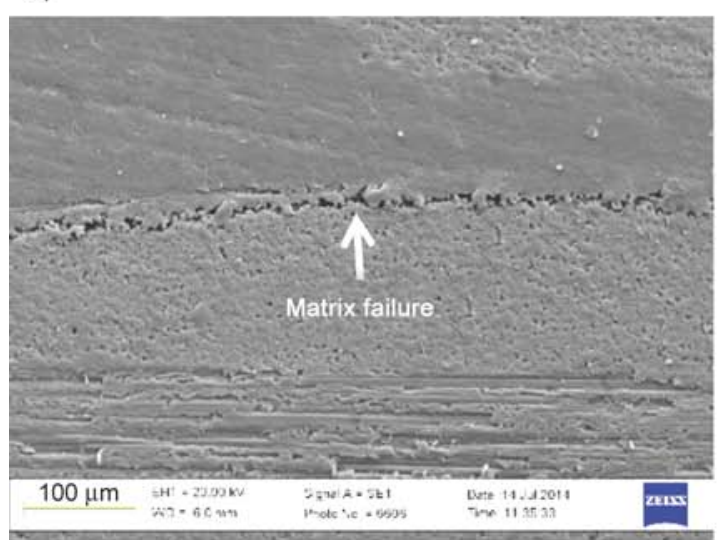

g)

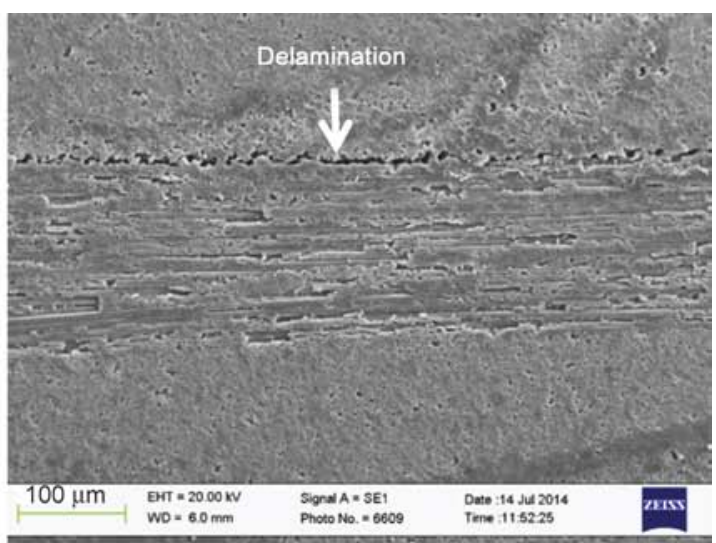

b)

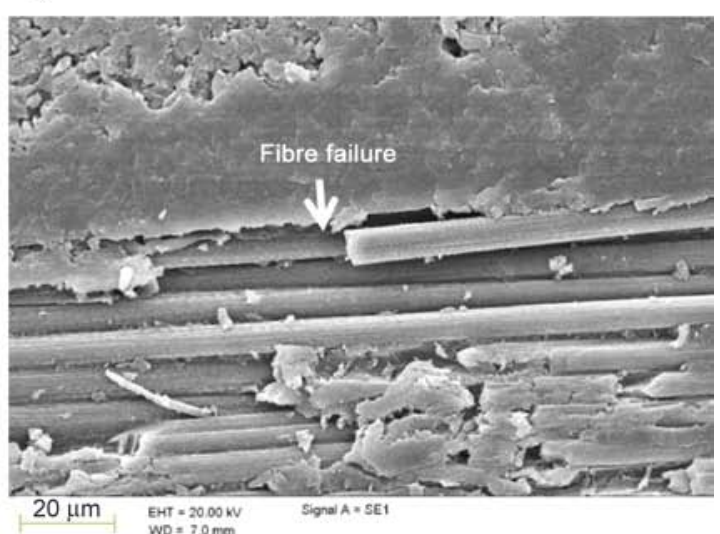

d)
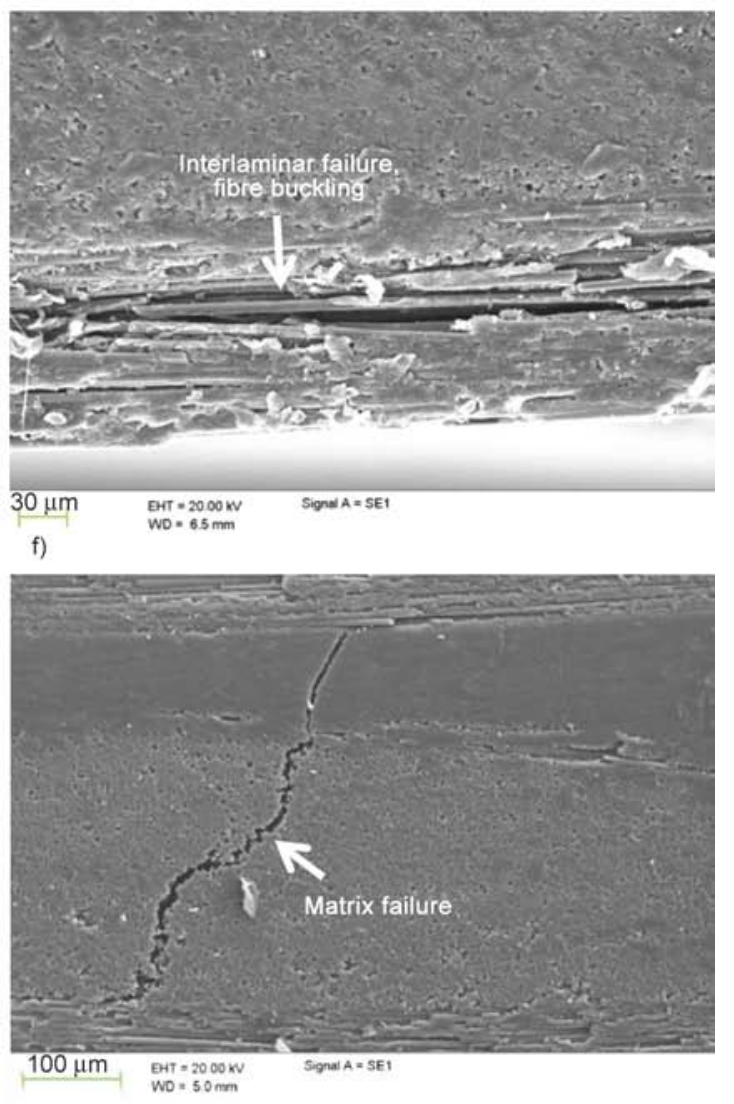

h)

Figure 5. (a, b) Edge view of CFRP with R/ 1FS matrix, (c, d) edge view of CFRP with 10CNBR-NP/ R matrix, (e, f) edge view of CFRP with 15CNBR-NP/ R matrix, (g, h) edge view of 20CNBR-NP/ R matrix 

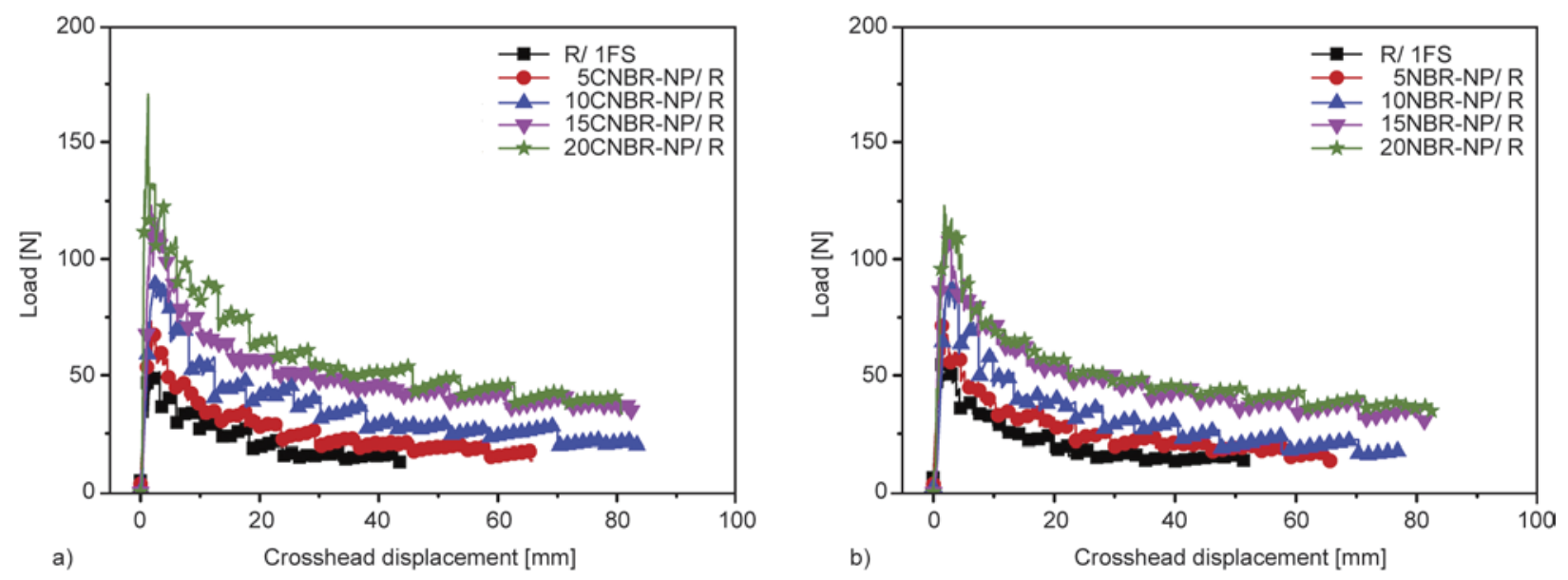

Figure 6. Load vs. crosshead displacement graph of DCB samples with (a) X CNBR-NP/ R matrix, (b) X NBR-NP/ R matrix

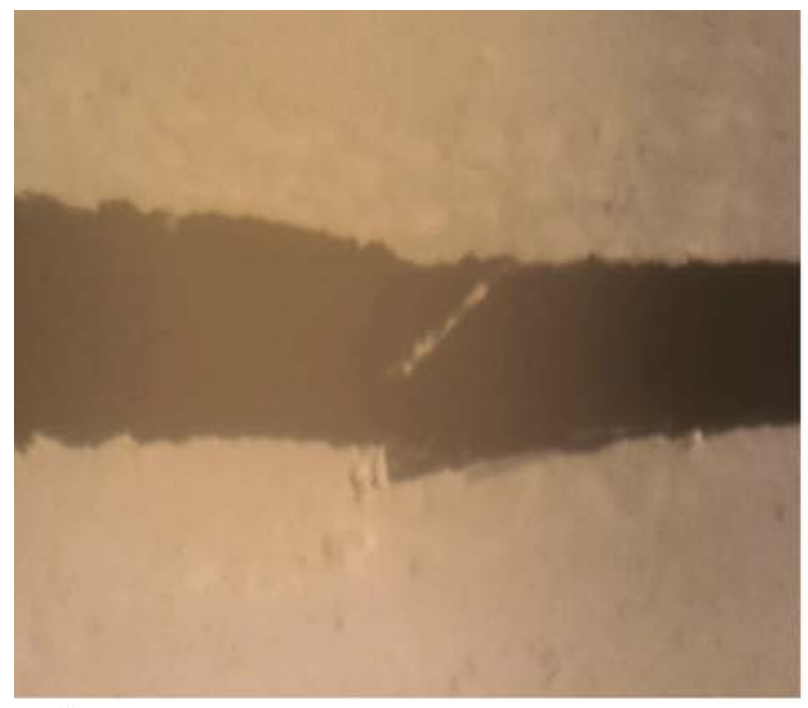

a)

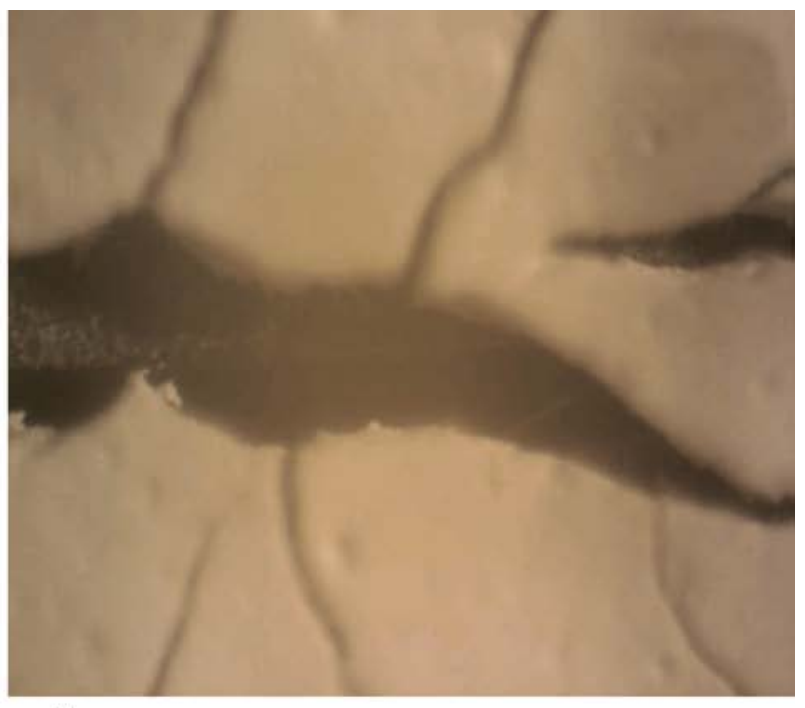

b)

Figure 7. Crack propagation in DCB test, (a) CFRP with R/ 1FS matrix, (b) CFRP with 20CNBR-NP/ R matrix

ture toughness. Hence, the enhanced interlaminar fracture toughness of CFRP panels with nanotoughened matrices is mainly attributed to the increased fracture surface area due to the microcracking and crack deflection [39].

The fracture surfaces of the DCB samples were further examined with SEM, and fibre breakage, interface debonding and delamination were observed in all of the composites configurations.

In Figures 8a) and 8b, the fracture surface of the CFRP with the unmodified epoxy matrix shows a typical brittle fracture with no plastic deformation. Slight fibre bridging can be observed in these images. Figures $8 \mathrm{c}$ and $8 \mathrm{~d}$ are the micrographs of the fracture surface of the sample with 20CNBR-NP/ R matrix that shows fibre bridging in higher aspects. This high amount of fibre bridging within the structures accounts for the high interlaminar fracture toughness values. In Figures $8 \mathrm{~d}$ and $8 \mathrm{f}$, holes can be observed on the fibre troughs, which may indicate that the nanoparticles have adhered to the carbon fibre surface. In Figures 8e and 8f, an even higher amount of tortuosity is observed due to good bonding of the NBR-NP modified resin matrix to the carbon fibre. Better adherence of the NBR-NP modified resin matrix to the fibres was also proved in Figure 2b.

\subsection{Mode II interlaminar fracture toughness (end notched flexure test)}

The Mode II fracture toughness data of CFRP samples obtained from ENF specimens are presented in Table 4. Mode II interlaminar fracture energy values are higher than Mode I values because the matrix crack propagation occurs in shear rather than tensile. There is a strong dependency of the Mode II frac- 


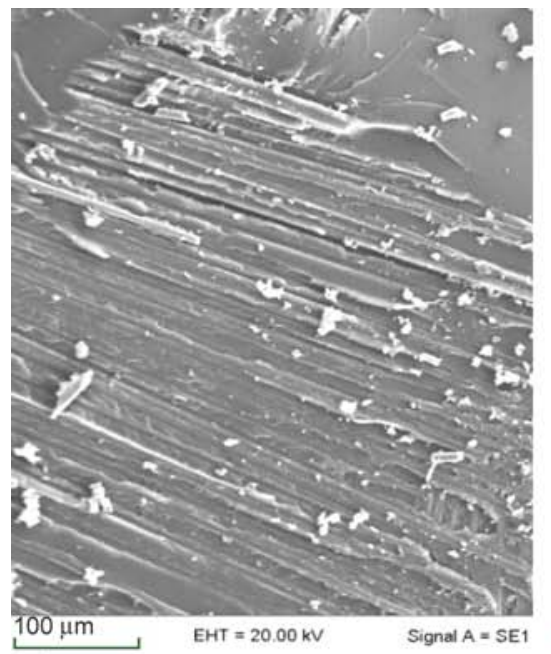

a)

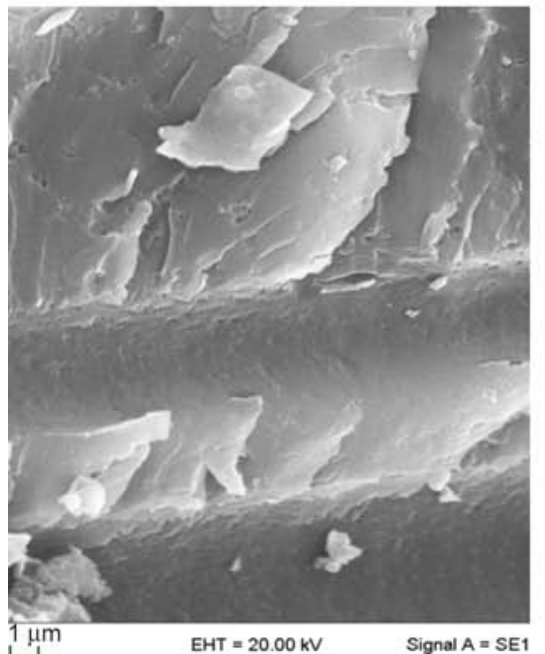

d)

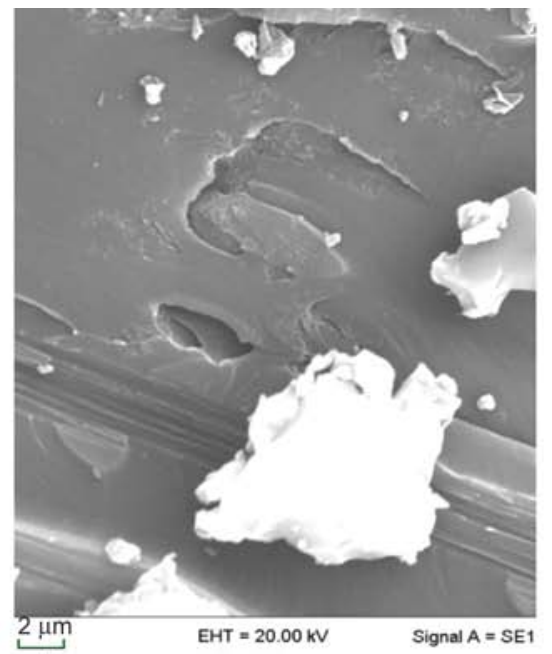

b)

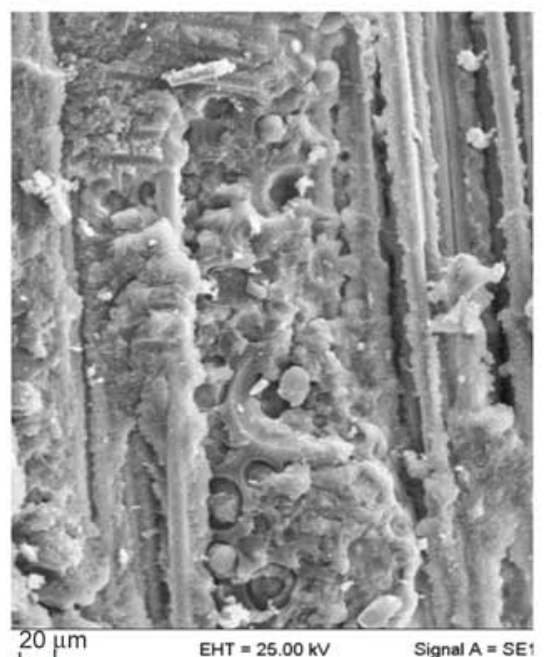

e)

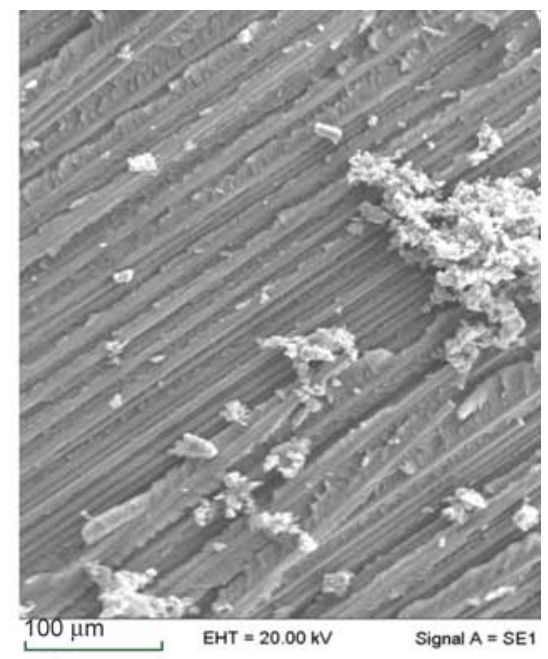

c)

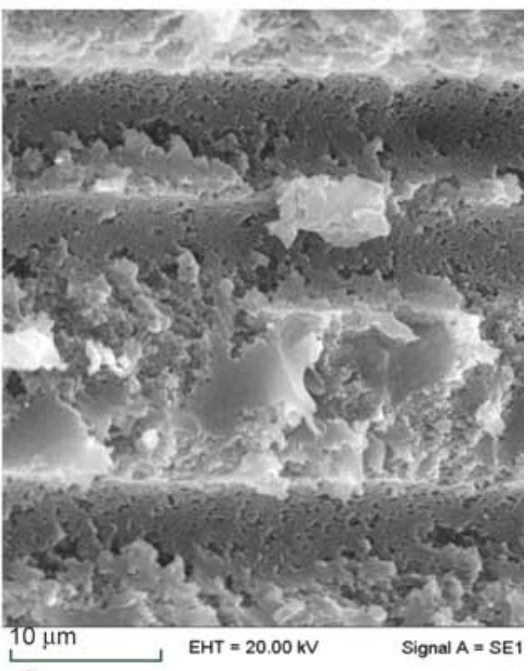

f)

Figure 8. SEM images of the fracture surfaces in DCB samples (a) and (b) laminate with R/ 1FS matrix, (c) and (d) laminate with 20CNBR-NP/ R matrix, (e) and (f) laminate with 20NBR-NP/ R matrix

ture toughness $\left(G_{\text {IIC }}\right)$ versus the fibre-matrix bonding. The increase in $G_{\text {IIC }}$ toughness with nano rubber concentration can be explained by good adhesion of the nano rubber toughened resin matrix to the carbon fibres (see Figure 8). When the fibre-matrix bonding is strong, energy absorbing phenomena such as matrix deformation, matrix cracking, fibre pull-out, and interfacial failure takes place. As a result, the $G_{\text {IIC }}$ of the composites shows a significant improvement. Figure 9 shows the corresponding load vs. displacement for the ENF samples. The load increases until

Table 4. $G_{\text {IIC }}$ test data, $\sigma$-standard deviation

\begin{tabular}{|c|c|c|c|c|c|c|}
\hline \multirow{2}{*}{$\begin{array}{c}\mathbf{X} \\
{[\mathbf{p h r}]}\end{array}$} & \multicolumn{2}{|c|}{$\mathbf{X} \mathbf{C N B R}-\mathbf{N P} / \mathbf{R}$} & \multicolumn{3}{|c|}{$\mathbf{X} \mathbf{N B R}-\mathbf{N P} / \mathbf{R}$} \\
\cline { 2 - 7 } & $\begin{array}{c}\boldsymbol{G}_{\mathbf{I C}} \\
{\left[\mathbf{J} / \mathbf{m}^{\mathbf{2}}\right]}\end{array}$ & $\begin{array}{c}\boldsymbol{\sigma} \\
{\left[\mathbf{J} / \mathbf{m}^{2}\right]}\end{array}$ & $\begin{array}{c}\mathbf{I n c r e a s e} \\
{[\mathbf{\%}]}\end{array}$ & $\begin{array}{c}\boldsymbol{G}_{\mathbf{I C}} \\
{\left[\mathbf{J} / \mathbf{m}^{\mathbf{2}}\right]}\end{array}$ & $\begin{array}{c}\boldsymbol{\sigma} \\
{\left[\mathbf{J} / \mathbf{m}^{2}\right]}\end{array}$ & $\begin{array}{c}\text { Increase } \\
{[\%]}\end{array}$ \\
\hline $0(1 \mathrm{FS})$ & 1090 & 103 & - & 1090 & 103 & - \\
\hline 5 & 1156 & 56 & 6 & - & - & - \\
\hline 10 & 1489 & 89 & 37 & 1739 & 69 & 60 \\
\hline 15 & 1823 & 122 & 67 & - & - & - \\
\hline 20 & 1976 & 46 & 81 & 2000 & 58 & 83 \\
\hline
\end{tabular}

the crack initiates and propagates, which then results in a decrease in load. Once the decrease in load was observed, the test was stopped. It can be seen that with an increase in nano rubber loadings, the maximum load attained before fracture and the displacement to failure increases.

\section{Conclusions}

In the present study, nano-sized CNBR and NBR rubber particles were used to improve the toughness of CFRP composites. Special emphasis was placed on the fracture toughness of two nano-acrylonitrile butadiene rubber toughened epoxy composites under mode I and mode II loading conditions. The most efficient dispersion technique was identified the nano rubber systems and the mechanical and morphological properties of carbon fibre laminate produced with these nano-modified matrices were studied in detail. 

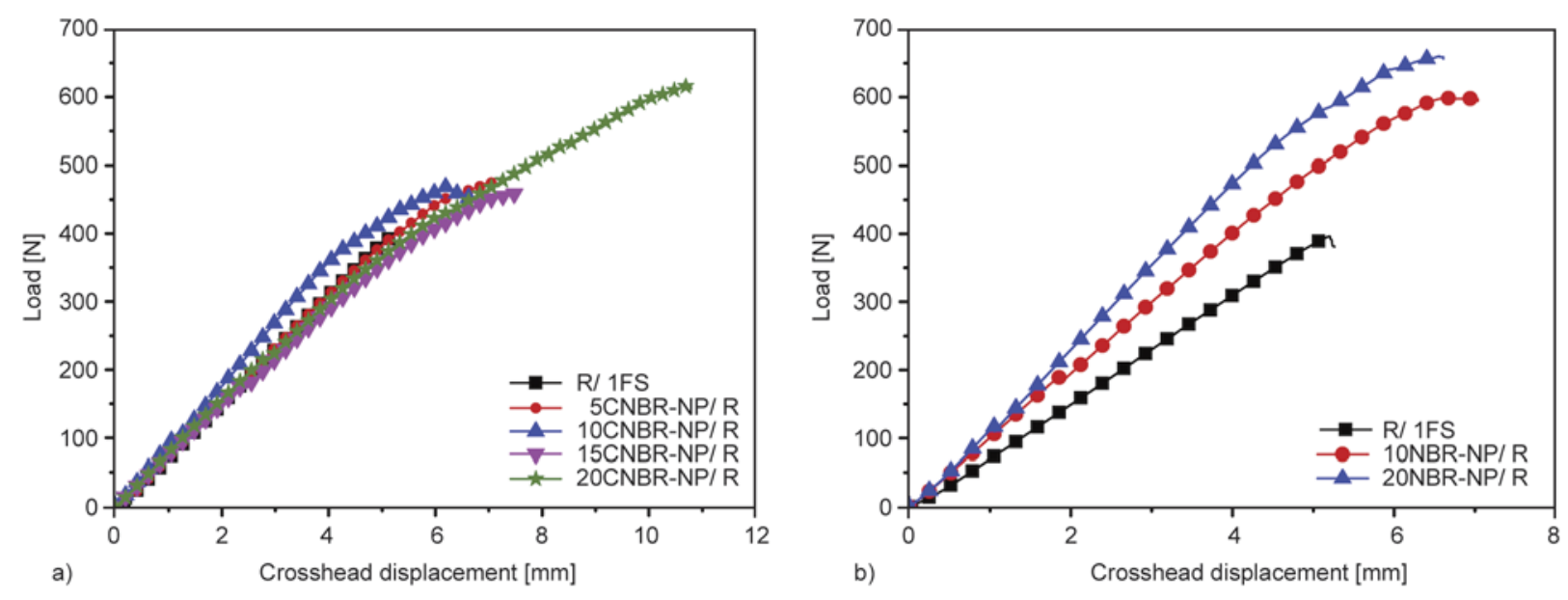

Figure 9. Load vs. crosshead displacement of the ENF samples with (a) X CNBR-NP/ R matrix, (b) X NBR-NP/ R matrix

The fracture toughness of the CFRP laminates improved significantly with the nano rubber modification of the matrix, which was justified by the changed morphology of the resins. $G_{\text {IC }}$ and $G_{\text {IIC }}$ toughness of CFRP panels were increased by 250 and $80 \%$ with rubber loading in both systems. The toughening mechanisms were identified as crack path deflection, debonding and micro-cracking of the rubber particles. The elastomeric nature of the nano rubbers caused a reduction in the interlaminar shear strength, indicating an enhancement of the flexibility of the CFRP composites with the dispersion of the nano rubber.

\section{Acknowledgements}

The research leading to these results has received funding from the FP7-MC-ITN under grant agreement No. 264710. The authors would like to thank the Directorate-General for Science, Research and Development of the European Commission for financial support of the research. The authors from Kingston University London would like to thank SINOPEC, Beijing Research Institute of Chemical Industry (BRICI), China and Cytec Industrial Materials for their kind supply of chemicals for the study.

\section{References}

[1] Shi H-Q., Sun B-G., Liu Q., Yang Z-Y., Yi K., Zhang Y., Fu S-Y.: A high ductility RTM epoxy resin with relatively high modulus and $T_{\mathrm{g}}$. Journal of Polymer Research, 22, 134/1-134/9 (2015). DOI: $10.1007 / \mathrm{s} 10965-015-0774-7$

[2] Nash N. H., Young T. M., McGrail P. T., Stanley W. F.: Inclusion of a thermoplastic phase to improve impact and post-impact performances of carbon fibre reinforced thermosetting composites - A review. Materials and Design, 85, 582-597 (2015).

DOI: $\underline{10.1016 / \mathrm{j} . \text { matdes.2015.07.001 }}$
[3] Zhou H., Xu S.: A new method to prepare rubber toughened epoxy with high modulus and high impact strength. Materials Letters, 121, 238-240 (2014).

DOI: $10.1016 /$ j.matlet.2014.01.160

[4] Thomas S.: Micro and nano structured epoxy rubber blends. Wiley, Weinheim (2014).

[5] Meng Q., Wang C. H., Saber N., Kuan H-C., Dai J., Friedrich K., Ma J.: Nanosilica-toughened polymer adhesives. Materials and Design, 61, 75-86 (2014). DOI: $10.1016 /$ j.matdes.2014.04.042

[6] Sprenger S., Kothmann M. H., Altstaedt V.: Carbon fiber-reinforced composites using an epoxy resin matrix modified with reactive liquid rubber and silica nanoparticles. Composites Science and Technology, 105, 86-95 (2014).

DOI: 10.1016/j.compscitech.2014.10.003

[7] Tang L-C., Wan Y-J., Yan D., Pei Y-B., Zhao L., Li Y-B., Wu L-B., Jiang J-X., Lai G-Q.: The effect of graphene dispersion on the mechanical properties of graphene/ epoxy composites. Carbon, 60, 16-27 (2013). DOI: $10.1016 /$ j.carbon.2013.03.050

[8] Qi G., Zhang X., Li B., Song Z., Qiao J.: The study of rubber-modified plastics with higher heat resistance and higher toughness and its application. Polymer Chemistry, 2, 1271-1274 (2011).

DOI: $10.1039 / \mathrm{COPY} 00413 \mathrm{H}$

[9] Phong N. T., Gabr M. H., Anh L. H., Duc V. M., Betti A., Okubo K., Chuong B., Fujii T.: Improved fracture toughness and fatigue life of carbon fiber reinforced epoxy composite due to incorporation of rubber nanoparticles. Journal of Materials Science, 48, 6039-6047 (2013).

DOI: $10.1007 / \mathrm{s} 10853-013-7400-\mathrm{Z}$

[10] Fan H., Liu Y., Zhang X., Gao J., Song Z., Tang B., Wei G., Qiao J.: Interface and properties of epoxy resin modified by elastomeric nano-particles. Science in China Series B: Chemistry, 48, 148-155 (2005). DOI: $10.1360 / 04 \mathrm{yb} 0022$ 
[11] Tripathi G., Srivastava D.: Effect of carboxyl-terminated poly(butadiene-co-acrylonitrile) (CTBN) concentration on thermal and mechanical properties of binary blends of diglycidyl ether of bisphenol-A (DGEBA) epoxy resin. Materials Science and Engineering: A, 443, 262-269 (2007).

DOI: $10.1016 /$ j.msea.2006.09.031

[12] Tang Y., Ye L., Zhang Z., Friedrich K.: Interlaminar fracture toughness and CAI strength of fibre-reinforced composites with nanoparticles - A review. Composites Science and Technology, 86, 26-37 (2013). DOI: $10.1016 /$ j.compscitech.2013.06.021

[13] Hsieh T. H., Kinloch A. J., Masania K., Lee J. S., Taylor A. C., Sprenger S.: The toughness of epoxy polymers and fibre composites modified with rubber microparticles and silica nanoparticles. Journal of Materials Science, 45, 1193-1210 (2010). DOI: $10.1007 / \mathrm{s} 10853-009-4064-9$

[14] Ozdemir N. G., Zhang T., Hadavinia H., Aspin I., Wang J.: Rheological properties, cure characteristics, and morphology of acrylonitrile-based nanorubber modified epoxy. Journal of Applied Polymer Science, 132, 41911/1-41911/13 (2015).

DOI: $10.1002 / a p p .41911$

[15] Ozdemir N. G., Zhang T., Hadavinia H., Aspin I., Scarpa F.: Influence of nanorubber toughening on the tensile deformation and tensile fatigue behaviour of a carbon fibre-reinforced epoxy composite. Journal of Composite Materials, in press (2015). DOI: $10.1177 / 0021998315609976$

[16] Acebo C., Alorda M., Ferrando F., Fernández-Francos X., Serra A., Morancho J. M., Salla J. M., Ramis X.: Epoxy/anhydride thermosets modified with end-capped star polymers with poly(ethyleneimine) cores of different molecular weight and poly( $\varepsilon$-caprolactone) arms. Express Polymer Letters, 9, 809-823 (2015). DOI: $10.3144 /$ expresspolymlett.2015.76

[17] Quan D., Ivankovic A.: Effect of core-shell rubber (CSR) nano-particles on mechanical properties and fracture toughness of an epoxy polymer. Polymer, 66, 16-28 (2015).

DOI: $10.1016 /$ j.polymer.2015.04.002

[18] Hsieh T. H., Kinloch A. J., Taylor A. C., Kinloch I. A.: The effect of carbon nanotubes on the fracture toughness and fatigue performance of a thermosetting epoxy polymer. Journal of Materials Science, 46, 7525-7535 (2011).

DOI: $10.1007 / \mathrm{s} 10853-011-5724-0$

[19] Wu S., Ladani R. B., Zhang J., Bafekrpour E., Ghorbani K., Mouritz A. P., Kinloch A. J., Wang C. H.: Aligning multilayer graphene flakes with an external electric field to improve multifunctional properties of epoxy nanocomposites. Carbon, 94, 607-618 (2015). DOI: 10.1016/j.carbon.2015.07.026
[20] Poisson N., Maazouz A., Sautereau H., Taha M., Gambert X.: Curing of dicyandiamide epoxy resins accelerated with substituted ureas. Journal of Applied Polymer Science, 69, 2487-2497 (1998).

DOI: 10.1002/(SICI)1097-4628(19980919)69:12<2487 $\because$ AID-APP20>3.0.CO;2-T

[21] Lee Y-D., Wang S-K., Chin W-K.: Liquid-rubber-modified epoxy adhesives cured with dicyandiamide. I. Preparation and characterization. Journal of Applied Polymer Science, 32, 6317-6327 (1986). DOI: 10.1002/app.1986.070320813

[22] Pegorin F., Pingkarawat K., Daynes S., Mouritz A. P.: Influence of z-pin length on the delamination fracture toughness and fatigue resistance of pinned composites. Composites Part B, 78, 298-307 (2015). DOI: 10.1016/j.compositesb.2015.03.093

[23] Gibson R. F.: Principles of composite materials mechanics. McGraw Hill, New York (1994).

[24] Drescher P., Thomas M., Borris J., Riedel U., Arlt C.: Strengthening fibre/matrix interphase by fibre surface modification and nanoparticle incorporation into the matrix. Composites Science and Technology, 74, 6066 (2013).

DOI: 10.1016/j.compscitech.2012.10.004

[25] Sae-oui P., Sirisinha C., Intiya W., Thaptong P.: Properties of natural rubber filled with ultrafine carboxylic acrylonitrile butadiene rubber powder. Advances in Polymer Technology, 30, 183-190 (2011). DOI: $10.1002 / \mathrm{adv} .20215$

[26] Kinloch A. J., Maxwell D. L., Young R. J.: The fracture of hybrid-particulate composites. Journal of Materials Science, 20, 4169-4184 (1985).

DOI: $10.1007 / \mathrm{BF} 00552413$

[27] Lee J., Yee A. F.: Role of inherent matrix toughness on fracture of glass bead filled epoxies. Polymer, 41, 83758385 (2000).

DOI: $10.1016 / \mathrm{S} 0032-3861(00) 00186-5$

[28] Williams J. G.: Particle toughening of polymers by plastic void growth. Composites science and technology, 70, 885-891 (2010). DOI: 10.1016/j.compscitech 2009.12.024

[29] Kawaguchi T., Pearson R. A.: The effect of particlematrix adhesion on the mechanical behavior of glass filled epoxies. Part 2. A study on fracture toughness. Polymer, 44, 4239-4247 (2003). DOI: $10.1016 / \mathrm{S} 0032-3861(03) 00372-0$

[30] Zamanian M., Mortezaei M., Salehnia B., Jam J. E.: Fracture toughness of epoxy polymer modified with nanosilica particles: Particle size effect. Engineering Fracture Mechanics, 97, 193-206 (2013). DOI: $10.1016 /$ j.engfracmech.2012.10.027

[31] Norman D. A., Robertson R. E.: Rigid-particle toughening of glassy polymers. Polymer, 44, 2351-2362 (2003). DOI: $10.1016 / \mathrm{S} 0032-3861(03) 00084-3$

[32] Huang Y., Kinloch A. J.: The role of plastic void growth in the fracture of rubber-toughened epoxy polymers. Journal of Materials Science Letters, 11, $484-487$ (1992). DOI: $10.1007 / \mathrm{BF} 00731112$ 
[33] Bai S. L., Djafari V., Andréani M., François D.: In situ study of short-beam shear tests for composite materials. Composites Science and Technology, 55, 343-348 (1995). DOI: 10.1016/0266-3538(95)00077-1

[34] Wisnom M. R., Reynolds T., Gwilliam N.: Reduction in interlaminar shear strength by discrete and distributed voids. Composites Science and Technology, 56, 93-101 (1996).

DOI: 10.1016/0266-3538(95)00128-X

[35] Singh S., Partridge I. K.: Mixed-mode fracture in an interleaved carbon-fibre/epoxy composite. Composites Science and Technology, 55, 319-327 (1995). DOI: 10.1016/0266-3538(95)00062-3

[36] Díez-Pascual A. M., Naffakh M., Gonzalez-Domínguez J. M., Ansón A., Martínez-Rubi Y., Martínez M. T., Simard B., Gómez M. A.: High performance PEEK/carbon nanotube composites compatibilized with polysulfones-I. Structure and thermal properties. Carbon, 48, 3485-3499 (2010).

DOI: $10.1016 /$ j.carbon.2010.05.046
[37] Siddiqui N. A., Woo R. S., Kim J-K., Leung C. C., Arshad M.: Mode I interlaminar fracture behavior and mechanical properties of CFRPs with nanoclay-filled epoxy matrix. Composites Part A: Applied Science and Manufacturing, 38, 449-460 (2007).

DOI: $10.1016 /$ j.compositesa.2006.03.001

[38] Grabr H. M., Abd Elrahamn M., Okubo K., Fujii T.: Interfacial adhesion improvement of plain woven carbon fiber reinforced epoxy filled with micro-fibrillated cellulose by addition liquid rubber. Journal of materials science, 45, 3841-3850 (2010). DOI: $10.1007 / \mathrm{s} 10853-010-4439-\mathrm{y}$

[39] Ozdemir N. G., Zhang T., Hadavinia H., Aspin I., Scarpa F.: Glass fibre reinforced polymer composites toughened with acrylonitrile butadiene nanorubber. Composites Part B: Engineering, 88, 182-188 (2015). DOI: $10.1016 /$ j.compositesb.2015.09.004 